\title{
BIRTH COMPLICATIONS CONTROL BETWEEN MIDWIVES AMONG WOMEN IN CROSS RIVER STATES-NIGERIA
}

OYIRA EMILIA JAMES AND N. C. ESSIEN

(Received 14 October 2016; Revision Accepted 14 December 2016)

\begin{abstract}
Objectives: This study sought to assess birth complications control between midwives among women in cross river states-Nigeria. To achieve this purpose, one null hypothesis was formulated to guide the study.

Method: The study adopted was survey design. The sample consisted of 360 post-natal women selected from a population of 78,814 through the polio immunization registers of selected health centers. Accidental sampling technique was used to select the respondents. The instrument used for collecting data for the study was a 36-item questionnaire. Independent t-test and contingency chi-square were used in testing the null hypotheses.

Results: The result showed that women delivered by traditional midwives have more negative control of delivery pain caused by birth complication than their counterparts who are delivered by western trained midwives; On the basis of finding it implies that western midwives are different from their counterparts. All what the traditional midwives need is workshops, seminars, conferences during ante-natal period to acquaint the traditional midwives with delivery related activities and procedures. It was also recommended that the traditional midwives should be given adequate training so that they can face the society and avoid further complications.
\end{abstract}

Conclusion: Government should also continue to train more midwives to avoid the patronage of traditional birth attendance because hospital is the best place for delivery.

KEYWORDS: Birth Complications, Control, Midwives, Women, Cross River State-Nigeria.

\section{INTRODUCTION}

In all societies today, the birth of a baby is a momentous occasion. The details of the experiences surrounding the whole event are etched on one's memory forever. Delivery pain is a global phenomenon experienced by every woman going through child delivery. This places huge responsibility on midwives in helping women through child delivery and are recognized worldwide in that capacity (Oyira, Duke, Essien, \& Onoyom 2015). The western midwife which is train midwife also has a key role to play in promoting the antenatal and postnatal health and well-being of childbearing women and their families (Cooper, 2003). Traditional midwives do the same but they cannot be considered as skilled providers. They hold a special position in many communities and should be considered part of the community's informal health care system. However, since they have no formal training on how to carry out their operation, they indulge in crude methods of delivery. Many women suffer complication under them. They suffer maternal and foetal complications and some even die in the process while the train midwives lack good behavior, and interpersonal relationship to patients (Oyira et al 2015). Experiences have shown that many women prefer going to traditional midwives than the hospital. Reasons are ascribed to time wasting, payment of bills, and lengthy "unnecessary" protocols.
Apart from this, some women/relatives feel that some western midwives have very unfriendly attitude which can cause spontaneous abortion. Besides, according to Oyira et.al (2015) when the client is due for delivery she must have to produce all necessary papers to prove that she has been consulting in that health center for the past six months. Even when this is done, there is always a deposit required to be paid before anything is done. Kitzinger (2000) asserted that while traditional midwives help mothers to wash napkins hospital midwives don't have such time. All of these make traditional midwives to win the confidence of women both in urban and rural areas. The understanding of the rural women in particular about the hospital is that it is a place for educated people and those who have money (Ihejiamaizu, 2002).

These complications cause by the traditional midwife arose because traditional midwives are not only ill-equipped for the job; they also lack knowledge of the full delivery process (Oyira, 2007). This in turn leads to unimaginable mismanagement of delivery complications such as;

Maternal exhaustion: This is a situation where a patient has labour for a very long period and becomes exhausted. Psychologically, the woman's morale is low and the threshold for pain is reduced she maybe out of control due to fear and anxiety pending it's out come. Under orthodox midwifery, such cases require an

Oyira Emilia James, Department of Nursing Science, University of Calabar, Calabar, C.R.S. Nigeria.

N. C. Essien, Department of Nursing Science, University of Calabar, Calabar, C.R.S. Nigeria. 
administration of five percent (5\%) dextrose (intravenously) to strengthen such women in labour. Where there is maternal exhaustion, second stage of labour is always delayed thus protecting the baby.

Retained placenta: This is inability of the placenta to come out after delivery of the baby and is common resulting from poor management of pregnancy such as over-massage of the uterus. Where such cases occur in the hospital, they are normally treated through the process of cauterization, but a traditional midwives lacks such medical skill.

Obstructed labour: This occurs as a result of excessive thinning of the lower segment of the cervix. It manifests with arising pulse rate atonic contractions, vaginal bleeding with excruciating pains. Most often, it may even lead to death if a surgical intervention is not immediately provided.

Acute inversion of the uterus: This is a situation where the uterus is turned inside out. It is a serious complication of the third stage caused by a forceful attempt to expel the placenta using fundal pressure when the uterus is atonic and this is associated with traditional midwives method of delivery.

Cervical tear: Most traditional midwives encourage their patients to bear down when the cervix is not fully dilated and the head not yet descended to the pelvic floor.

Perineal laceration: Is a laceration that occurs when the perineum is not well guarded and this practice is associated with traditional midwives. In hospital deliveries episiotomy is given to extend the perineum, in traditional delivery, there is nothing like that, laceration may lead to excessive vaginal opening of the patient.

Post-partum hemorrhage: It is the excessive bleeding during the $3^{\text {rd }}$ stage of labour or within 24 hours after expulsion of placenta which is due to mismanagement. Where the above situation occurs, it is always very difficult to control. Also massaging, squeezing and pushing over stimulate the uterus thereby causing irregular contraction and partial separation of the placenta. All the complications may appear very strange to a traditional midwives.

Puerperal sepsis: Is another complication associated with traditional deliveries. It is an infection of the genital tract by organisms occurring within $14^{\text {th }}$ days after childbirth. The maternal mortality rate due to puerperal sepsis is relatively high among women who patronize traditional midwives. They lack antiseptic techniques aimed at controlling the spread of infection.

Anemia/congestive cardiac failure: This can also develop due to excessive loss of blood causing anemia with no means of replacement, while congestive cardiac failure is also prevalent when changes occur in the contractile ability of the heart, it attempts to cope with the disruption by developing mechanisms to handle alterations in muscle contractility. When these mechanisms fail, cardiac out-put diminishes and heart failure results.

Vesico vaginal fistula: These is a trauma or injury to the bladder as a result of pressure from the fetal head during labour or as a result of trauma during delivery which is always associated with undiluted cervix carry out by traditional midwives (Oyira et al, 2015).

Some women go as far as booking for caesarian section for fear of delivery pain. However, the actual pain experience by a woman during delivery is caused by the uterine contractions, the dilatation of the cervix, and in the late stage and second state, by stretching of the vagina and pelvic floor to accommodate the neonate. These painful stimuli are transmitted by thoracic lumber of her pain control and also assist the traditional midwife on how they should alley patients of their anxiety during delivery pain. Government on their own part have tried as much as possible to train the western midwives whose responsibilities are to diagnose and monitor pregnancies, labours, and post partum progress, to work with child bearing women and other health care professional to achieve the best possible outcome for each individual family. The heads of department in the hospitals on their own part now being worried about most midwives attitude, try to organize continuing education to train the western midwives on their attitude towards their clients. Be that as it may majority of trained midwives are still showing negative attitude towards their clients. Some women prefer going to traditional midwives because of the following reasons: proximity, religious reason, social reason, economic reason and socio-cultural reasons.

The depth and the extent of this problem showed that clients do not actually know the right place to go and as such, women should be educated on the importance of hospital and the purpose of having to go to hospital for safe delivery (Oyira et al, 2015). The society sees the western nurses as people who are very wicked, rude, and unreliable. The resultant effect is the patronage of the traditional midwives. Most pregnant women need adequate psychological preparation by trained midwives so that they can go through labour ordeal with courage. Workshops, seminars and conferences should be organized during antenatal period to acquaint pregnant women with delivery related activities/experience. Women should be told about the stages of labour in simple terms. It is particularly important to explain that the first stage of labour is long compared to the second stage and during the first stage the cervix is being opened up, and that, there will be no sensation of progress or decent of the baby. This study is therefore being carried out as an effort to help the health care system solve the problem of birth complication control between midwives among women. The study is directed at determining the difference between women who delivered through trained midwives and those delivered through traditional midwives in their control of birth complication.

\subsection{Statement of the problem}

Initially, going to hospital for most mothers was a pleasant adventure but observation over the year's shows that a good number of mothers don't like hospital, don't like nurses. Mothers who attend antenatal clinic in the hospital at the end of the day divert their attention to traditional midwives because of the love of traditional midwives. However, the patronage of traditional midwives is not always a success story. Many women on child delivery suffer complications, which they cannot handle, such as, maternal exhaustion, retained placenta, obstructed labour, acute inversion of the uterus, cervical tear, perineal laceration, post-partum hemorrhage, puerperal sepsis, urinary tract infection, anemia, puerperal hemorrhage, vesico-vagina fisstular and intra 
uterine hyposiz which is in line with (Oyira et al 2015). The depth and the extent of this problem indicate that, clients do not make a right choice of where to be for their child delivery. It is therefore, necessary to educated mothers on the importance of patronizing trained midwives in the hospital for safe deliveries. Unfortunately, however the society sees the nurses as people that are very wicked, rude and as such cannot relied on them. Observations have shown that, pregnant mothers need adequate psychological preparation by trained midwives under western education so that they can go through labour ordeal with courage. This is based on the belief that traditional midwives lack knowledge of the factors which related to the control of delivery pain in Cross River State. Interms of complications and risk at birth.

\subsection{Purpose of the study}

The purpose of this study was to determine if midwives trained under the western educational background differs from the traditional background with regards to their effectiveness in delivery birth complication control among women in Cross River State, Nigeria. Specifically, the study was aimed at determining the difference between women who delivered through the trained midwives and those who delivered through traditional educational system in their:

i) Control of birth complications;

\section{$1.4 \quad$ Research question}

The research question was posed to guide the study.

1) To what extent do trained under the western educational background of midwives differ from those trained under traditional educational background with regard to their effectiveness in controlling delivery pain arising from birth complication.

\subsection{Statement of hypothesis}

The hypothesis was formulated to direct the study.

1) Trained under the trained midwives do not differ significantly from traditional midwives in their control of delivery pain caused by birth complications.

\subsection{Significant}

It is expected that the findings of this study might be of significance to the following: trained under western midwives, health personnel, pregnant mothers, traditional midwives, policy makers, women in general, government and researchers.

The findings of this study may further justify the urgent need to review the existing policy on ante-natal services at Federal, State and Local Governments.

The data generated in the study would provide empirical basis for evaluating trained and traditional midwives of health promotion in general and delivery services in particular.

The empirical result of the study is likely to provide a basis for the establishment of comprehensive antenatal health care services for pregnant mothers in rural communities of Cross River State of Nigeria. The result of this study may sensitize women in general and pregnant mothers in particular on the utilization of antenatal health services for the preparation of delivery pains birth complication control.

\subsection{Goals}

Our goals is to provide solutions/remedies and actions that will reduce maternal and fetal complications in our communities, state and the nation, Nigeria.

\section{$2.0 \quad$ Literature review}

The focus of this section is literature review.

2.1 Control of women towards delivery pain caused by complications at birth by trained and traditional midwives

According to Callisgter, Vega \& Khalag (2002)

there may be no complication in the first stage of normal human birth. The first stage is contractions. Complications occur in the second stage-delivery, which may be due to delays in second stage caused by:

i) mal-presentation of the fetal head

ii) failure of descent of the fetal head through the pelvic brim or the interspinous diameter

iii) poor uterine contraction strength

iv) a big baby and a small pelvic

v) may include shoulder dystocia

According to Oyira, these factors will lead to prolongation of the second stage of labour. Secondary changes may be observed. Swelling of the tissues, maternal exhaustion and foetal heart rate abnormalities. Left untreated, severe complications including death of mother or baby, and genitiovaginal fistula could result. These are commonly seen in third world countries where births are often unattended or attended by poorly trained community members. Infant death (neonatal deaths from birth to 28 days, or perinatal death if including fetal deaths at 28 weeks gestation and later) are around $1 \%$ in modernized countries. The maternal mortality (MMR) (2007) rate varies from $9 / 100,000$ live birth in the US and Europe, to $900 / 100,000$ lives births in sub-Sahara Africa. The "natural" mortality rate of childbirth-where nothing is done to avert maternal death-has been estimated as being between 1,000 and 1,500 deaths per 100,000 births. The most important factors affecting mortality in children are adequate nutrition and access to quality medical care (access is affected both by the cost of available care, and distance from health services). "Medical care" in this context does not refer specifically to treatment in hospital, but simply routine prenatal care and the presence, at the birth of an attendant with birthing skills. A 1983-1989 study by the Texas Department of Health highlighted the differences in neonatal mortality (NMR) between high risk and low risk pregnancies. NMR was $0.57 \%$ for doctor attended high risk births and $0.19 \%$ for low risk births attended by nonnurse midwives. Conversely, some studies demonstrate a higher perinatal mortality rate with assisted home births. Around $80 \%$ of pregnancies are low-risk. Factors that may make a birth high-risk include prematurity, high blood pressure, gestational diabetes and a previous caesarean section (Niven \& Brodie, 1995).

Birthing complication may be maternal or fetal, and long term or short term. 


\section{MATERNAL RISK}

Hemorrhage: is still the biggest killer of birthing mothers in the world today especially in the developing world. Heavy blood loss leads to hypovolemic shock, insufficient perfusion of vital organs and death if not rapidly treated. Blood transfusion may be life saving. Rare sequelae include hypopituitarism sheehan's syndrome.

Infection: remains a major cause of mortality and morbidity in the developing world today. The work of Ignaz Semmelweis was seminal in the pathophysiology and treatment of puerperal fever and saved many lives (Maternal and Neonatal Health, 2007).

Vaginal birth injury: visible tears or episiotomy are common. Internal tissue tearing as well as nerve damage to the pelvic structure lead in a proportion of women to problems with prolapsed, incontinent of stool or urine and sexual dysfunction. Fifteen (15\%) percent of women become incontinent to some degree of stool or urine after these women reach menopause. Vaginal birth injury is a necessary but not sufficient cause of all non hysterectomy related prolapsed in later life. Risk factor of significant vaginal birth injury includes:

1) A baby weighing more than nine kilogram

2) The use of forceps or vacuum for delivery. These markers are more likely to be signals for other abnormalities as forceps or vacuum are not used in normal deliveries.

3) The need to repair large tears after delivery (Maternal and Neonatal Health, 2007).

Pelvic girdle pain: hormones and enzymes work together to produce ligamentous relaxation and widening of the symphysis pubis during the last trimester of pregnancy. Most girdle pain occurs before birthing and is known as diastasis of the pubis symphysis. Predisposing factors for girdle pain include maternal obesity.

Intrapartum asphyxia: the term fetal distress is emotive and misleading. True intrapartum asphyxia is the impairment of oxygen to the brain and vital tissue during the progress of labour. This may exist in a pregnancy already impaired by maternal or fetal disease, or may rarely arise in labour. True intrapartum asphyxia is not as common as previously believed and is usually accompanies by multiple other symptoms during the immediate period after delivery. Monitoring might show up problems during birthing, but the interpretation and use of monitoring device is complex and prone to misinterpretation (Maternal and Neonatal Health, 2007).

Mechanical fetal injury: risk factors for fetal birth injury include fetal macrosomia (big baby), maternal obesity, the need for instrumental delivery, and an inexperienced attendant. Specific situations that can contribute to birth injury include breech presentation and shoulder dystocia. Most fetal birth injuries resolve without long term harm, but brachial plexus injury may lead to Erb's palsy.

Neonatal infection: neonates are prone to infection in the first month of life. Some organisms such as sagalactiae (group B streptococus) or (GBS) are more prone to cause these occasionally fatal infections. Risk factors for GBS infection include:

Prematurity

a sibling who has had a GBS infection

prolonged labour or rupture of membrances

Footing breech (in which leg or both legs are positioned to enter the birth canal) are not considered safe to attempt virginal delivery. This is one of the three ways of breech presentation. A slowing of labour or any indication of differently in the body passing through the pelvic should be an indication that it is safer to consider a cesarean section. Complications can come from forceps deliveries. Sometimes they may cause nerve damage or temporary damage to the baby's face but when used by an experienced physician, forceps can save the life of a baby in distress. The vacuum extractor is not as likely as forceps to injure the mother and it leaves more room for the baby to pass through the pelvis. The force of the suction may cause a bruise on the baby's head but it fades away in a day. However, there may be problems in maintaining the suction during the vacuum assisted birth, so forceps may be a better choice if it is important to remove the baby quickly. Difficult labour is commonly caused by one of the three following conditions: abnormalities in the mother's birth canal, abnormalities in the position of the foetus; abnormalities in the labour, including weak or infrequent contractions. Another major factor is fetal distress, a condition where the foetus is not getting enough oxygen. Foetal distress is often related to abnormalities in the position of the foetus, or abnormalities in the birth canal, causing reduced blood flow through the placenta. Other conditions can also make cesarean section advisable, such as vaginal herpes, (high blood pressure) and diabetes in the mother. Transverse lie (this is where the baby is sideway in the womb) C-section is divided (Niven \& Brodie, 1995).

In developing countries in Africa, the patronage of traditional midwives is not all that a successful story. They also suffer maternal and fetal complication or even death.

Maternal: Common maternal complications experienced in developing countries of Africa include:

Retained placenta: this occurs due to poor management of pregnancy such as over-massage of the uterus. In the hospital, they are treated through the process of cauterization when it occurs but with traditional midwives, the solution may be far, or through prayers.

Maternal exhaustion: some women cannot eat during labour till after child birth, in the hospitals. Such cases require an administration, through infusion of five (5\%) percent dextrose, intravenously to strengthen such woman. Second stage of labour is usually delayed to protect the baby in such cases.

Cervical tear: most traditional midwives encourage their patients to bear down when the cervix is not fully dilated and the head is not yet descent to the pelvic floor. 
Perineal lacerations: in hospital deliveries, episiotomy is given to extend the perineum, but with traditional midwives, this is lacking and may lead to excessive vaginal opening for the women if not properly taken care of. Urinary tract infections may also occur due to difficult labour. Anaemia/congestive cardiac failure can also develop due to excessive loss of blood with no means of replacement.

Acute inversion of the uterus: is a process where the uterus is turned inside out. This is serious complication of the third stag caused by a forceful attempt to expel the placenta using fungal pressure when the uterus is atonic and it is very common with traditional birth attendant's method of delivery.

Obstructed labour: it occurs as a result of excessive thinning of the lower uterine segment. It occurs with rising pulse rate, tonic contractions, vaginal bleeding with excruciating pains. It often leads to death if a surgical intervention is not immediately done.

Post-partum hemorrhage: this is caused due to mismanagement. It is the excessive bleeding during the third stage of labour or within 24 hours after expulsion of placenta. Massaging, squeezing and pushing, over stimulates the uterus, thereby causing irregular contractions and partial separation of the placenta. This may be very strange to a traditional birth attendant.

Puberal hemorrhage: though bleeding may take place from the 24 hours up to the sixth week of the pueperium but it commonly occurs between $10^{\text {th }}$ and $14^{\text {th }}$ days. This is due to retention of a piece of placenta. This is common with the traditional birth attendants because, they do not inspect their patients after delivery.

Vesisco-vaginal fistula (VVF) is the artificial opening between the umbilical cord and the vagina. It is caused by prolonged pressure by the foetal head during labour (Callisgter, Vega \& Khalag, 2002).

\section{Foetal complication}

In the third world countries of Africa foetal complication may be similar with other parts of the world. But there may be little difference such as:

Intra uterine hyposiz: Traditional midwives lack medical expertise of administering oxygen to the mother and this may lead to foetal distress. Finally, it results in still birth or intra-uterine death (IUD)

Serious cases of infection: neonatal infection becomes a major problem among the traditional midwives due to poor and unhygienic handling of the umbilical cord.

Mayan women living in Guatemala who gave birth at home were attended by village midwives and supported by female extended family members. Those who gave birth in public hospitals were largely unattended and unmedicated (Oyira, Duke, Essien, \& Onoyom 2015).

\section{0}

Research Methods

In this section, the focus will be on the research methodology. It is set forth under the following subheadings.

\subsection{Research design}

The research design adopted in this study was survey. In a survey design, according to Isangedighi, Joshua, Asim \& Ekuri (2004), the researcher attempts to obtain a picture of the present conditions of particular phenomena. It is directed towards determining the nature of a situation, as it exists at the time of investigation and it depends basically on questionnaire and interviews as means of data collection. This particular research design was adopted because the variables under study were examined as they existed when the study was carried out. The study also involves very large populations that were only covered through a sample using questionnaires and describing the picture of the situation instead of drawing inference. In this study, the independent variables, trained midwives and traditional midwives, was a measure of difference; while dependent variables already exist in the control of delivery pain of women.

\subsection{Research area}

The area covered by this study is Cross River State of Nigeria. Cross River State is located in the South Eastern flank of the Federal Republic of Nigeria in what is known as the south-south zone, between latitude $5^{0} 32$ and $4^{0} 27$ north of the equator, and longitude $7^{0} 50$ and $9^{\circ} 28$ east of the Greenwich meridian.

Cross River State as it exists today consists of eighteen (18) local government areas namely; Abi, Akamkpa, Akpabuyo, Bakassi, Bekwarra, Biase, Boki, Calabar Municipality, Calabar South, Etung, Ikom, Obanliku, Obudu, Obubra, Odukpani, Ogoja, Yakurr and Yala.

According to the state ministry of lands and surveys, the state occupies a land mass of $23,074,425$ square kilometers. The population has been estimated at about 2.6 million people by the states planning commission and national population commission respectively.

The state is bounded in the north by Benue State, in the south by the Atlantic Ocean, in the west by Akwa Ibom State and Abia State to the North West by Ebonyi State and to the east by the Republic of Cameroon.

For proper supervision of health centres, the health centres and hospitals in the state are divided into three Senatorial Districts.

Southern Senatorial District

Central Senatorial District

Northern Senatorial District

\subsection{Population of the study}

The population of this study is made up of all post-natal women in Cross River State, who have their 
names registered as mothers into the state polio immunization registers in 2009. The comprehensive register available at all local government health centers with the state show that there were a total of $(78,814)$ seventy-eight thousand, eight hundred and fourteen postal-natal women in the state during the period. A breakdown of the population figure is shown in the Table 1.

\subsection{Sampling procedure}

Two sampling techniques were adopted in selecting the sample for the study. These are the simple random and accidental sampling techniques. The former was used in selecting equal number of Local Government Areas (LGAs) for the study from each of the three Senatorial Districts.
Four Local Government Areas were selected from the Southern District, three from the Central and two from the Northern Senatorial Districts. From ach Local Government Area, 40 respondents were used for the study.

To carry out the selection of health centres all the names of the centres in each Local Government Areas were written down on a piece of paper and then subjected to selection through simple random sampling technique of the fact that all health centres have polio immunization registers with the addresses of contact families in them.

The post-natal women were reached through the polio immunization registers of the selected health centres.

Table 1: Study population by senatorial district and local government area

\begin{tabular}{|l|l|l|}
\hline $\begin{array}{l}\text { Senatorial } \\
\text { District }\end{array}$ & Local Government Areas & $\begin{array}{l}\text { No. } \\
\text { Women }\end{array}$ \\
\hline Southern & Bakassi & 312 \\
& Akpabuyo & 3,358 \\
& Calabar Municipality & 5,051 \\
& Calabar South & 4,972 \\
& Odukpani & 4,215 \\
& Akamkpa & 3,119 \\
& Biases & 6,012 \\
& Total & 27,039 \\
\hline Central & Yakrr & 6,218 \\
& Abi & 4,964 \\
& Obubra & 5,097 \\
& Ikom & 5,136 \\
& Etung & 2,425 \\
& Boki & 5,611 \\
& Total & 29,451 \\
\hline Northern & Obanliku & 4,222 \\
& Obudu & 3,961 \\
& Bekwarra & 5,725 \\
& Ogoja & 3,853 \\
& Yala & 4,563 \\
& Total & 22,324 \\
\hline & Grand & 78,814 \\
\hline
\end{tabular}

The accidental sampling technique was used in selecting the women for the study. This technique is normally used for convenience when other techniques seem difficult to apply. A total of 415 post-natal women were reached and administered questionnaires. From this number 360 questionnaire of women who have delivered in only one of government hospital/health centre of traditional delivery home were finally selected as sample.

For this study the researcher visited as many families found in the register as possible until they require number of questionnaires (for both women who delivered in government hospital/health centres and in the traditional centres) were completed.

\subsection{Sample}

The sample for this study was made up of 360 post-natal women selected from nine (9) Local Government Areas across the three Senatorial Districts of Cross River State, Nigeria. Out of the 360 women selected, 160 were from the southern Senatorial District, 120 from the Central Senatorial District and 80 from the Northern Senatorial District.

\subsection{Instrumentation}

The instrument for the study is a 36 item questionnaire called control of delivery pain questionnaire (PDPQ). The questionnaire is divided into two sections ( $A$ and $B$ ). Section $A$ is on personal data and is made up of 7 items. Section B is on control of delivery pain and it is sub-divided into five sub-sections with six items each. The sub-section is on control of pain from risk and complications.

\subsection{Validity of the instrument}

In order to validate the instrument, control of delivery pain inventory (PDPI) questionnaire copies were presented to the researcher's supervisor and 
experts in measurement to scrutinize for face validity.

Face validity of an instrument is obtained through a superficial examination of content of the research instrument and the establishment of the fact that the content can measure what it wants to measure (Kerlinger, 1987).

\subsection{Reliability of the instrument}

In order to determine the reliability of the instrument, a trial test was conducted with a group of 50 post-natal women in Akwa lbom State. The 50 postnatal women who took part in the study were capture twice during polio immunization week. The researcher employed five health staff who did not take part in the immunization and attached each of them to a team to collect data from mothers as the children were being immunized. This was done twice during two consecutive immunizations.

During the second data collection exercise the employed assistant for the trial test were made to repeat the immunization areas they covered in the first test to ensure that the women who completed the questionnaire in the first visit were spotted and made two questionnaire responses for the 50 respondents were then used for a test-retest reliability estimate. The results of the estimate are presented in Table 2.

\subsection{Data collection procedure}

The questionnaire was administered by the researcher, assisted by some health staff that were employed by the researcher.

Table 2: Test-retest reliability estimates of variables on control of delivery pain among post-natal women ( $\mathrm{N}=50)$

\begin{tabular}{|l|l|l|l|l|l|}
\hline Independent variable & $\begin{array}{l}\text { No. of } \\
\text { items }\end{array}$ & Administration & $\mathbf{X}$ & SD & rxx \\
\hline $\begin{array}{l}\text { Control of women towards delivery pain } \\
\text { caused by complications at birth }\end{array}$ & 6 & $\begin{array}{l}1^{\text {st }} \\
2^{\text {nd }}\end{array}$ & 12.49 & 2.84 & 0.65 \\
\hline
\end{tabular}

Source: Fieldwork, 2010

The respondents were visited at their individual homes using the addressed of the polio immunization registers kept at the various health centers.

Literate women were allowed to tick the questionnaire after a thorough explanation of the instructions, while illiterate women were assisted by the researcher or her assistants as the case may be by reading out the items in the language understood by the respondents (using an interpreter). The researcher and her assistant waited at each home and retrieved copied of the questionnaire the very moment they were completed.

\subsection{Procedure for data preparatory}

The two sections of the questionnaire were coded separately and scored following a four (4) point Likert scale format ranging from very strongly agrees (VSA) to very strongly disagree (VSD). The following scores were attached to responses on the side.

\section{Response}

Very strongly agree (VSA)

Agree (A)

Disagree (D)

Very strongly disagree (VSD)

\section{Score \\ 4 points \\ 3 points \\ 2 points \\ 1 point}

Scoring was reversed for items that were negatively worded with a score of 4 reversed to 1 for a very strongly disagree response and vice versa.

\subsection{Procedure for data analysis}

The following procedures were adopted in testing each of the hypotheses.

\section{Hypothesis one}

Trained under western education do not differ significantly from traditional midwives in their control of delivery pain caused by complications and risk at birth.
Independent variable: type of midwives

Dependent variable: control of delivery pain as caused by complications and risk at birth.

Test statistic used: Independent t-test analysis

\subsection{RESULTS AND DISCUSSION}

This section is on the data analysis relevant to the study, presentation of results obtained from the analysis and the discussion of findings.

\subsection{General description of research/variable}

The study was on the western and traditional educational background of midwives and delivery pain control in Cross River State, Nigeria. The independent variable of the study is place of delivery categorized in this study into two, namely; delivery through trained midwives and delivery through traditional midwives. Data for this variable was nominal and was collected through a personal data item in section $A$ of the questionnaire. This item requested respondents to tick ( $)$ who they have experienced child delivery under whether it was under a trained midwife, traditional midwives or under both. No respondent said she had been delivered by both. Of the 360 respondents, $221(61.4 \%)$ said they were delivered by trained midwives while $139(38.4 \%)$ said they were delivered by traditional midwives.

\subsection{PRESENTATION OF RESULTS Hypothesis}

Trained under western education do not differ significantly from traditional midwives in their control of delivery pain caused by birth complications.

Independent t-test statistical technique was used in analyzing data for this hypothesis. The results of the analysis are presented in Table 3. 
Table 3: Independent t-test analysis of the influence of western education of midwives on delivery pain caused by birth complications

\begin{tabular}{|l|l|l|l|l|}
\hline Variables & $\mathrm{N}$ & $\mathrm{X}$ & $\mathrm{SD}$ & $\mathrm{t}$ \\
\hline $\begin{array}{l}\text { Delivery pain control by trained under western education caused by } \\
\text { birth complication }\end{array}$ & 221 & 20.38 & 3.660 & \\
\hline $\begin{array}{l}\text { Delivery pain control by traditional midwives caused by birth } \\
\text { complications }\end{array}$ & 139 & 11.84 & 4.850 & $18.95^{\star}$ \\
\hline
\end{tabular}

*significant at $.05 ; \mathrm{df}=358$; critical $\mathrm{t}=1.96$

Source: Fieldwork, 2010

Results of analysis in Table 3 show that the calculated t-value of 18.951 is greater than the critical tvalue of 1.95 at .05 level of significance with 358 degrees of freedom. This means that trained midwives differ from traditional midwives in their control of delivery pain caused by birth complications. That is, trained midwives are more positive in delivery pain control through the management of complication than their counterparts who traditional midwives.

\subsection{DISCUSSION OF FINDINGS}

Control of women towards delivery pain caused by complications and the risk at birth by both trained under western education and traditional educational system

Results from research findings show that women who deliver under trained midwives differ significantly from women who deliver under traditional midwives. This finding is in line with Callister, Vega \& Khalay (2002) who concluded that complication occur in the second stage caused by:

i) mal-presentation of the fetal head

ii) failure of the descent of the fetal head through the pelvic brim or the inter spinous diameter

iii) poor uterine contraction strength

iv) a big baby and a small pelvic

v) may include shoulder dystocia

This is also in line with Oyira et al (2016) who states that these factors will lead to prolongation of the second stage of labour, which may look strange to the traditional midwives. Secondary changes may be observed; swelling of the tissues or liabia, major, maternal exhaustion, and foetal heart rate abnormalities, serve complications including death of mother or baby. Observation over the years by the researcher shows that common maternal complication experienced in developing countries of Africa include: retrained placenta, maternal exhaustion, cervical tear, perineal lacerations, urinary tract infection, anaemia, acute inversion of the uterus, obstructed labour post partum hemorrhage, puberal hemorrhage and vesisco-vaginal fistula with the factors stated trained midwives differ significantly from the traditional midwives in their control of delivery pain caused by complications and the risk at birth.

From the following its means that traditional midwives cannot actually cope with the process of delivery pain caused by complication and the risk at birth. The study also revealed that complications are commonly seen in third world countries where birth are often unattended or attended by poorly trained community members some studies also demonstrated a higher perinatal mortality rate with assisted home births. Around $80 \%$ of pregnancies are low-risk factors that may make a birth high-risk include prematurity, high blood pressure, gestational diabetes and a previous ceasarian section. This shows that trained midwives differ significantly from traditional midwives. Common maternal complications experienced in developing countries of Africa include:

1) Retained placenta: This occurs due to poor management of pregnancy such as overmassage of the uterus. In the hospital, they are treated through the process of cauterization when it occurs but with traditional midwives, the solution may be far, or through prayers.

2) Maternal exhaustion: Some women cannot eat during labour till after child birth, in the hospitals. Such cases require an administration, through infusion of five (5\%) percent dextrose, intravenously to strengthen such woman. Second stage of labour is usually delayed to protect the baby in such cases (Oyira, Mgbekem et al 2016).

3) Cervical tear: Most traditional midwives encourage their patients to bear down when the cervix is not fully dilated and the head is not yet descent to the pelvic floor.

4) Perineal lacerations: In hospital deliveries, episiotomy is given to extend the perineum, but with traditional midwives, this is lacking and may lead to excessive vaginal opening for the women if not properly taken care of.

5) Urinary tract infections may also occur due to difficult labour.

6) Anaemia/congestive cardiac failure can also develop due to excessive loss of blood with no means of replacement.

7) Acute inversion of the uterus: Is a process where the uterus is turned inside out. This is serious complication of the third stage caused by a forceful attempt to expel the placenta using fungal pressure when the uterus is atonic and it is very common with traditional birth attendants' method of delivery (Oyira, Onoyom, 2016).

8) Obstructed labour: It occurs as a result of excessive thinning of the lower uterine segment. It occurs with rising pulse rate, tonic contrations, vaginal bleeding with excruciating pains. It often leads to death if a surgical intervention is not immediately done.

9) Post-partum hemorrhage: This is caused due to mismanagement. It is the excessive bleeding during the third stage of labour or within 24 
hours after expulsion of placenta. Massaging, squeezing and pushing, over stimulates the uterus, thereby causing irregular contractions and partial separation of the placenta. This may be very strange to a traditional birth attendant. Puberal hemorrhage: Though bleeding may take place from the 24 hours up to the sixth week of the pueperium but it commonly occurs between $10^{\text {th }}$ and $14^{\text {th }}$ days. This is due to retention of $a$ piece of placenta. This is common with the traditional birth attendants because, they do not inspect their patients after delivery.

11) Vesisco-vaginal fistula (VVF) is the artificial opening between the umbilical cord and the vagina. It is caused by prolonged pressure by the foetal head during labour (Oyira, Mgbekem, Osuchukwu, Onoyom, Lukpata, Ojong-Alasia, 2016).

\subsection{SUMMARY}

A high level of negative control of delivery pain has been observed among women and it has become a matter of great concern leading to infant and maternal mortality rate; this study ventured to find out the negative control delivery pains by women who delivered through trained under western education and traditional educational system of midwives.

Particularly, the study investigated women who deliver through trained and traditional midwives in their control of birth complication.

The focus of this of this study was all postnatal women. The study area was Cross River State which comprised of 18 Local Government Areas. The population was made up of seventy eight thousand, eight hundred and fourteen $(78,814)$ postnatal women from polio immunization register kept at the various health centers. The sample comprised of 360 postnatal women selected from the polio immunization register at each health centers.

Data were obtained by means of questionnaire specially developed for the study. Independent t-test analysis was used for data analysis. The finding revealed that:

Trained midwives under western education differ significantly from traditional midwives in their control of birth pain caused by complications. That is, women who delivered under trained midwives had a more positive control birth pain caused by complications than their counterparts who delivered under traditional midwives. These complications arose because traditional midwives are not only ill-equipped for the job; they also lack knowledge of the full delivery process. This in turn leads to unimaginable mismanagement of delivery complications. While trained midwife's under western education skill and judgment are crucial factors in minimizing maternal trauma and ensuring an optimal birth for both mother and the baby. These qualities are acquired by experience but certain basic principles should be applied whatever the expertise of the midwife. They observed the progress of labor, prevention of infection, anticipation of normal events, and recognition of abnormal developments. This shows that the trained midwives are better than their counterpart.

\section{CONCLUSION}

From the research findings, the following conclusion could be made. The quality and quantity of hospital facilities provided in different hospital determine the quality of the job done by the trained under western system. Any midwives with a good control of delivery pain as a mean of achieving the goals of health care delivery services.

Since the traditional midwives is not paid by the government. It is possible that their control of delivery pain would not necessarily affect their performance. Patients cooperate especially when they realize that their midwives have genuine consideration for them.

Multiple roles arising from negative attitude of trained under western education midwives does not affect the professional effectiveness because responsibilities are shared among the midwives. Multiple roles performed by the midwife result into negative attitude which may be stressful for the midwife and may affect the way she communicates to her patients.

Lack of praises, reassurance education will increase patient anxiety and fear during delivery process. Lack of government assistant on the part of the traditional midwives will give rise to delivery complications.

Giving traditional midwives the privilege of participating in decision making in terms of setting goals or contributing their ideas in decision affecting them, their patients or overall health care delivery system is not a mark of recognition or job efficiency.

\section{RECOMMENDATIONS}

1) Traditional midwives under western education should be encouraged and sponsored to attend professional conferences, seminars, and workshops in their discipline.

2) Trained midwives under western education should take notice of the factors in professional effectiveness and employ them when performing the roles. It is only when they have done this, that there will be more productive.

3) Trained midwives under western education should learn to cope with stressful situation in their place of work. One-way of coping with stress is self-monitoring which enables you control a situation.

4) Traditional midwives needs to be motivated so that they feel satisfied and work effectively in our communities. In an attempt to motivate them, the principal need is to provide psychological support and encouragement in terms of rewards, example provision of simple kits for delivery and other facilities.

5) Trained midwives under western education should be encouraged to develop and sustained a better control of their job in all relevant areas.

6) The society should be encouraged through public enlightenment campaign on the need to develop a positive image of the trained midwives under western education.

\section{SUGGESTIONS FOR FURTHER RESEARCH}

It is suggested that further investigations be carried out into: 
1) Further studies should also utilize observational technique, interview methods, and written materials to evaluate actual delivery processes by both trained under western education and traditional educational system.

2) Further studies should investigate women who have been delivered by both western and traditional educational system at different intervals.

3) The relative effectiveness of occupational stress on both western and traditional midwives professional effectiveness should be experimentally investigated at all level of our work environment.

\section{REFERENCES}

Callister, L. L., Vega, R and Khalag., 2002. Giving birth Guatemala women's voice. Journal of Obstetrics, Gynecologic and Neonatal. Nursing, 27, 289-295.

Cooper, M. A., 2003. Textbook for midwives ( $4^{\text {th }}$ ed.). London: oxford University Press.

Inejiamaizu, E. C., 2002. Issues in population policy and health care administration. Calabar: Africa Scholars Publishers.

Isangedighi, A., Joshua, M., Asim, A and Ekuri, E.,

2004. Fundationals of research and statistics in education and social science. Calabar: University of Calabar Press.

Kerlinger, F. N., 1987. Foundational of behavioural research. New York: Holt Phinehart and Winston.

Kitzinger, S., 2000. Some cultural perspective of birth. British Journal of Midwifery, 8(12), 746750.http://dx.doi.org/10.129654/bjom.2000.8.12. 8037

Maternal and Neonatal Health (MMH)., 2007. The traditional birth attendant! Nairobi: university of Nairo and population council.
Niven, C and Brodie, E., 1995. Memory for labour pain: content and quality pain 64:387-39 http:dxdoi.org/10./016/0304-3959(95)00134-4

Oyira, E. J and Affiong Ekpenyong Onyom., 2016. Perception of vesicovaginal fistula among women being managed at the centre for the treatement of birth related injuries, Mbri-Mbri Itam, Uyo. International Journal of Scientific Innovation and sustainable development, 6, (1):1-12.

Oyira, E. J., 2007. Socio-cultural factors influencing umbilical cord management in Northern Cross River State of Nigeria. International Professional Nursing Journal, 5, (1): 132-142.

Oyira, E. J., Duke, U. E., Essien, N. C and Ekpenyoung.

A. O., 2015. Western and traditional educational background of midwives and delivery pain control among women in Cross River States, Nigeria (3) 33-44 http://dx.doi.org/10.11114/jets.v.3i3.728

Oyira, E. J., Mgbekem, M., Osuchukwu, E. C., Affiong, E. O., Lukpata, F. E., Ojong, A and Mary. M., 2016. Delivery pain anxiety/fear control between midwives among women in cross river statesNigeria.URL:http://dx.doi.org/10.11114/jets.4/i3. 1346 